\title{
Energy Band and Absorption Coefficient of Quantum Dots in a Well Structur
}

\author{
P. Zhang, X.-C. Lu, C.-L. Zhang And J.-H. YaO* \\ Key Laboratory of Weak-Light Nonlinear Photonics, Ministry of Education, School of Physics \\ and TEDA Applied Physics School, Nankai University, Tianjin 300457, P.R. China
}

(Received December 18, 2011; in final form April 15, 2012)

\begin{abstract}
Building on the effective-mass envelope function theory, this paper focuses on the study of the energy band and the absorption coefficient of $\operatorname{InAs} / \operatorname{In}_{x} \mathrm{Ga}_{1-x} \mathrm{As}$ quantum dots in a well (DWELL) structure. In contrast to InAs $/ \mathrm{In}_{0.15} \mathrm{Ga}_{0.85} \mathrm{As}$ quantum DWELL, the $\operatorname{InAs} / \mathrm{In}_{0.2} \mathrm{Ga}_{0.8}$ As quantum DWELL has lower ground states. With the thickness of $\operatorname{In}_{0.15} \mathrm{Ga}_{0.85}$ As layer changing from $7 \mathrm{~nm}$ to $9 \mathrm{~nm}$ and $\operatorname{In}_{0.2} \mathrm{Ga}_{0.8}$ As layer changing from $9 \mathrm{~nm}$ to $12 \mathrm{~nm}$, the calculation shows that their absorption coefficient spectra takes a red shift in the long-wave infrared and far-infrared ranges, respectively. Moreover, when the thickness of the $\operatorname{In}_{x} \mathrm{Ga}_{1-x}$ As layer is defined as $9 \mathrm{~nm}$, the absorption coefficient spectra of $\mathrm{InAs} / \mathrm{In}_{0.2} \mathrm{Ga}_{0.8} \mathrm{As}$ DWELL shows a obvious red shift comparing with that of InAs $/ \mathrm{In}_{0.15} \mathrm{Ga}_{0.85} \mathrm{As}$ DWELL.
\end{abstract}

PACS: 73.21.La, 73.63.Kv

\section{Introduction}

In the last decades, there have been significant concerns about quantum dots (QDs) [1-5]. The interband and intersubband transitions of these QDs are utilized to develop QD infrared photodetectors, contrasted with quantum well infrared photodetectors, which presents lower dark currents and unlimited incidence. Meanwhile, these QD infrared photodetectors have been applied successfully to detecting infrared light detectors, sensors and imaging devices. However, under the condition of spontaneous growth techniques which has been widely adopted nowadays, it is difficult to tailor the size and shape of the $\mathrm{QD}$, which leads to the out of control for the operating wavelength. In order to solve these problems, a new method is developed, which is to add a layer to the existing quantum dots to form so-called quantum dots in a well structure [6].

Recently, many experimental and theoretical researches on the DWELLs have been carried out [7-23]. It is demonstrated in experiment that the operating wavelength and dominant transition can be controlled through changing the thickness of layers. Meanwhile, the theoretical researchers on the QDs and DWELLs also have made much progress in which the quantum dot often has a cylinder or square pyramid shape. However, the QD is with an ellipsoid shape in experiments. Thus, the view of the QD with an ellipsoid shape is more close to the experiment which will be insisted in this paper.

According to the above, on the basis of the effective-mass envelope-function theory, we put emphasis on calculating the energy band and absorption coefficient of

\footnotetext{
* corresponding author; e-mail: yaojh@nankai.edu.cn
}

our mode, in which the quantum dot has an ellipsoid shape. Particular attention is paid to the changing of energy band and absorption coefficient, which arise from changing the value of $x$ in $\operatorname{In}_{x} \mathrm{Ga}_{1-x} \mathrm{As}$ and the thickness of layers.

The following part is organized as follows. In Sect. 2, by means of the effective-mass envelope-function theory, the formulation for absorption coefficient is derived. In Sect. 3, we present the numerical results and relevant discussion. Finally, a brief summary is offered in Sect. 4.

\section{Theoretical model}

The structure of DWELL applied is shown in Fig. 1. The growth direction (100) is defined as the $Z$ direction. InAs dots are located at the center of a thin $\operatorname{In}_{x} \mathrm{Ga}_{1-x} \mathrm{As}$ well, which is surrounded by a GaAs matrix in turn. We can treat the spatial distribution of InAs dots in the $\mathrm{In}_{x} \mathrm{Ga}_{1-x} \mathrm{As}$ as well as periodically arranged boxes; $2 h$ is the vertical height and $w$ is the width of the $\operatorname{In}_{x} \mathrm{Ga}_{1-x} \mathrm{As}$ well. The period for the unit cell is $L_{z}$ in the growth direction and $L$ in the parallel direction.

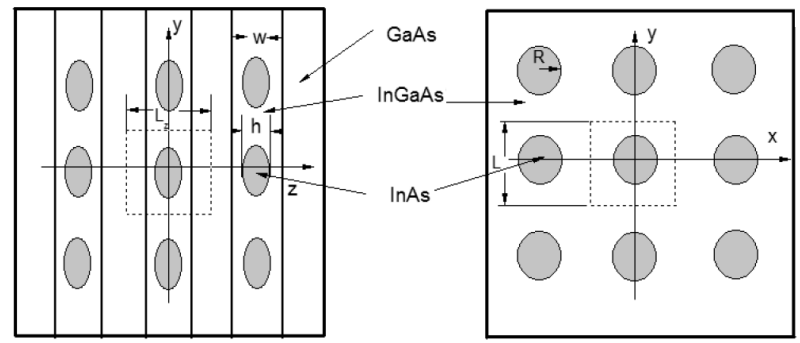

Fig. 1. Structure of the $\operatorname{InAs} / \operatorname{In}_{x} \mathrm{Ga}_{1-x} \mathrm{As}$ quantum dots-in-a-well heterostructure. 
In the effective-mass approximation the electron envelope-function equation can be expressed as

$$
\left[P \frac{1}{2 m^{*}(x, y, z)} P+V(x, y, z)\right] \psi=E \psi,
$$

where $m^{*}(x, y, z)$ is the electron effective mass and $V(x, y, z)$ is the potential experienced by the electron. They are given by

$$
\begin{aligned}
& m^{*}(x, y, z) \\
& \quad=\left\{\begin{array}{l}
m_{1}^{*}, \quad x^{2}+y^{2} \leq R^{2}\left(1-\frac{z^{2}}{h^{2}}\right), \\
m_{2}^{*}, \quad-\frac{L_{Z}}{2} \leq Z<-\frac{w}{2} \text { or }-\frac{w}{2}<Z \leq-\frac{L_{Z}}{2}, \\
m_{3}^{*}, \quad \text { others, }
\end{array}\right.
\end{aligned}
$$

and

$$
\begin{aligned}
& V(x, y, z) \\
& =\left\{\begin{array}{cc}
0, & x^{2}+y^{2} \leq R^{2}\left(1-\frac{z^{2}}{h^{2}}\right), \\
V_{1}, & -\frac{L_{Z}}{2} \leq Z<-\frac{w}{2} \text { or }-\frac{w}{2}<Z \leq-\frac{L_{Z}}{2}, \\
V_{2}, & \text { others. }
\end{array}\right.
\end{aligned}
$$

The electron envelope function is given by

$$
\begin{aligned}
& \psi(r)=\frac{1}{L \sqrt{L_{Z}}} \sum_{n_{x}, n_{y}, n_{z}} C_{n_{x}, n_{y}, n_{z}} \\
& \quad \times \exp \left(\mathrm{i}\left(k_{n x} x+k_{n y} y+k_{n z} z\right)\right),
\end{aligned}
$$

where $k_{n x}=k_{x}+n_{x} k_{x}, k_{n y}=k_{y}+n_{y} k_{y}, k_{z}=k_{Z}+n_{Z} k_{Z}$, $n_{x}, n_{y}, n_{z}=0, \pm 1, \pm 2, \pm 3$. Substituting Eqs. (2), (3) and (4) into Eq. (1), we can get the following secular equation:

$$
\begin{aligned}
& \operatorname{det}\left\{\left[\frac{\hbar^{2}}{2 m_{2}^{*}} \delta_{n_{x} n_{x}^{\prime}} \delta_{n_{y} n_{y}^{\prime}} \delta_{n_{z} n_{z}^{\prime}}+\frac{\hbar^{2}}{2 m_{12}^{*}} S_{i}\right.\right. \\
& \left.\quad+\frac{\hbar^{2}}{2 m_{32}^{*}}\left(\delta_{n_{x} n_{x}^{\prime}} \delta_{n_{y} n_{y}^{\prime}} \delta_{n_{z} n_{z}^{\prime}}-S_{j}\right) \delta_{n_{x} n_{x}^{\prime}} \delta_{n_{y} n_{y}^{\prime}}\right] \\
& \quad \times\left(k_{n x} k_{n x}^{\prime}+k_{n y} k_{n y}^{\prime}+k_{n z} k_{n z}^{\prime}\right) \\
& \quad+\left[V_{2} \delta_{n_{x} n_{x}^{\prime}} \delta_{n_{y} n_{y}^{\prime}} \delta_{n_{z} n_{z}^{\prime}}-V_{2} S_{i}+\left(V_{1}-V_{2}\right)\right. \\
& \left.\quad+\left(\delta_{n_{x} n_{x}^{\prime}} \delta_{n_{y} n_{y}^{\prime}} \delta_{n_{z} n_{z}^{\prime}}-S_{j}\right) \delta_{n_{x} n_{x}^{\prime}} \delta_{n_{y} n_{y}^{\prime}}\right] \\
& \left.\quad-E \delta_{n_{x} n_{x}^{\prime}} \delta_{n_{y} n_{y}^{\prime}} \delta_{n_{z} n_{z}^{\prime}}\right\}=0,
\end{aligned}
$$

where $k_{n x}^{\prime}=k_{x}+n_{x}^{\prime} K_{x}, k_{n y}^{\prime}=n_{y}^{\prime} K_{y}, k_{n z}^{\prime}=k_{z}+n_{z}^{\prime} K_{z}$, and

$$
\begin{aligned}
& \frac{1}{m_{12}^{*}}=\frac{1}{m_{1}^{*}}-\frac{1}{m_{2}^{*}}, \\
& \frac{1}{m_{32}^{*}}=\frac{1}{m_{3}^{*}}-\frac{1}{m_{2}^{*}}, \\
& S_{i}=\int_{\operatorname{dot}} \psi(r) \psi^{*}(r) \mathrm{d} r, \\
& S_{j}=\left\{\begin{array}{cc}
\frac{w}{L_{z}}, & n_{z}=n_{z}^{\prime}, \\
\frac{\sin \left(\left(n_{z}-n_{z}^{\prime}\right)\left(w / L_{z}\right) \pi\right)}{n_{z}-n_{z}^{\prime}}, & n_{z} \neq n_{z}^{\prime} .
\end{array}\right.
\end{aligned}
$$

The value of $S_{i}$ in Eqs. (8) can be calculated under the Gauss approximation method by computer. By solving
Eqs. (5), we can obtain the electron subband energies and wave functions of the DWELL structure. The strain effects are considered during the calculation. Knowing the energy levels and wave function, the matrix elements between two subband states can be determined in the effective-mass approximation. We concentrate on transitions $0 \rightarrow n$ and ignore the transitions such as $1 \rightarrow n$ $[17,23]$. Thus, the absorption coefficient is given by $[22,23]:$

$$
\begin{gathered}
\alpha(\hbar \omega)=\frac{8 \pi e^{2}}{n_{\mathrm{r}} c \omega m^{* 2}} \sum \int \frac{\mathrm{d} k}{(2 \pi)^{3}}\left|\left\langle\psi_{n}\left|H^{\prime}\right| \psi_{0}\right\rangle\right|^{2} \\
\times \frac{\Gamma}{\pi\left[\left(E_{n}-E_{0}-\hbar \omega\right)^{2}+\Gamma^{2}\right]}\left[f_{0}(k)-f_{n}(k)\right],
\end{gathered}
$$

where $n_{\mathrm{r}}$ is the refractive index and $H^{\prime}$ represents the interaction Hamiltonian between a free electron and a radiation field $[17,22] . f_{n}(k)$ are the electron occupancies. According to the Fermi distribution, the Fermi level can be determined by a given electron concentration $N$ :

$$
N=2 \int_{\mathrm{BZ}} \sum_{n} f_{n}(k) \mathrm{d} k /(2 \pi)^{3},
$$

where $\Gamma$ is the homogeneous part of the transition line width $[21,22]$.

\section{Results and discussion}

In this section, we carry out the numerical study of the energy of conduction band and absorption coefficient of our model. In the calculation, since the GaAs substrate is much thicker than the $\mathrm{InAs} / \mathrm{In}_{x} \mathrm{Ga}_{1-x}$ As layers, we hold that all strains are accommodated in the InAs/ $\mathrm{In}_{x} \mathrm{Ga}_{1-x} \mathrm{As}$ layers. Inserting an $\mathrm{In}_{x} \mathrm{Ga}_{1-x} \mathrm{As}$ layer between InAs QDs and the GaAs layer will allow partial strain relief, which is not considered here. When the QD size is small enough, electrons in the dot will have an essential portion of their wave function extending into the InGaAs/GaAs barriers. This accounts for the phenomena that the electron effective mass in the strained dot is close to that of the barrier material. However, the size of our QDs is not very small ( $\approx 7.5 \mathrm{~nm}$ in height). For this reason, the difference in the effective mass between the InAs dot and the $\mathrm{Ga}(\mathrm{In}) \mathrm{As}$ barrier is taken into account. The parameters of $\operatorname{In}_{x} \mathrm{Ga}_{1-x}$ As are interpolated from the values of InAs and GaAs, which are listed in Table.

The strain-dependent energy gap $\operatorname{In}_{x} \mathrm{Ga}_{1-x} \mathrm{As}$ is calculated by

$$
\begin{aligned}
& E_{\mathrm{g}}=E_{\mathrm{g}}^{0}+\left[2 a\left(C_{11}-C_{12}\right) / C_{11}\right. \\
& \left.\quad-b\left(C_{11}+2 C_{12}\right) / C_{11}\right] \varepsilon,
\end{aligned}
$$

where $a$ and $b$ are the hydrostatic and shear stress deformation potentials, respectively, $C_{i j}$ are the elastic constants, $\varepsilon$ is the lattice mismatch between $\operatorname{In}_{x} \mathrm{Ga}_{1-x} \mathrm{As}$ and $\mathrm{GaAs}$, and $E_{\mathrm{g}}^{0}$ is the composition-dependent band gap of unstrained $\operatorname{In}_{x} \mathrm{Ga}_{1-x}$ As. The temperatures of all parameters are neglected. The ratio of the conduction-band offset to the band gap difference is assumed to be $60 \%$. 
Material parameters for $\operatorname{In}_{x} \mathrm{Ga}_{1-x}$ As as a function of the In mole fraction $x$.

TABLE

\begin{tabular}{c|c|c|c|c|c|c}
\hline \hline$E_{\mathrm{g}}^{0}[\mathrm{eV}]$ & $a[\mathrm{eV}]$ & $b[\mathrm{eV}]$ & $C_{11}\left[10^{11} \mathrm{dyn} / \mathrm{cm}^{2}\right]$ & $C_{12}\left[10^{11} \mathrm{dyn} / \mathrm{cm}^{2}\right]$ & $\varepsilon$ & $m_{e}^{* c}$ \\
\hline $1.4525-1.501 x+0.436 x(300 \mathrm{~K})$ & $8.67-5.66 x$ & $1.7+0.1 x$ & $11.81-3.481 x$ & $5.32-0.794 x$ & $0.0717 x$ & $0.067-0.0285 x$ \\
$1.519-1.584 x+0.475 x^{2}(2 \mathrm{~K})$ & & & & &
\end{tabular}

First, we take different parameter $x$ in $\operatorname{In}_{x} \mathrm{Ga}_{1-x} \mathrm{As}$ as $x=0.15$ in Fig. $2 \mathrm{a}$ and $x=0.2$ in Fig. $2 \mathrm{~b}$. As a function of the dot radius $(R)$, the conduction subbands of the DWELL heterostructure is shown in Fig. 2. The other parameters are set as the same in Fig. 2a and Fig. 2b, namely, $L=15 \mathrm{~nm}+2 R, h=7.5 \mathrm{~nm}, w=12 \mathrm{~nm}$ and $L_{z}=60 \mathrm{~nm}$.

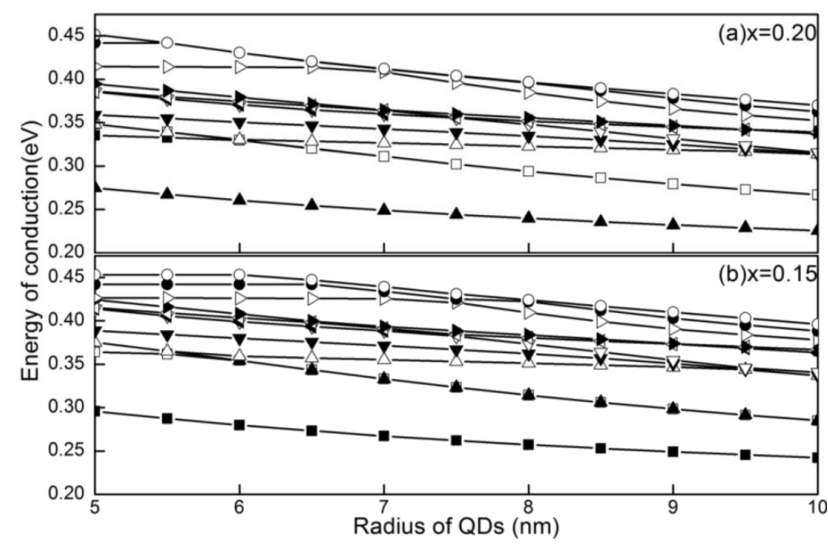

Fig. 2. Conduction subbands of (a) $\operatorname{InAs} / \operatorname{In}_{0.2} \mathrm{Ga}_{0.8} \mathrm{As}$ and (b) InAs $/ \operatorname{In}_{0.15} \mathrm{Ga}_{0.85}$ As DWELL.

In Fig. 2a and b, with increase of the dot radius $(R)$ in the DWELL, the subband energies decrease. It can be believed that this phenomenon arises from the quantum size effects. Comparing Fig. 2b with Fig. 2a, it can be seen that the ground state is lower in Fig. 2a than that in Fig. 2b. For example, when $R=5 \mathrm{~nm}$, the ground energy is $0.295 \mathrm{eV}$ in Fig. $2 \mathrm{~b}$ and $0.275 \mathrm{eV}$ in Fig. 2a. It is believed that the electrons at the ground state in the dots have a larger binding energy in InAs/ $\mathrm{In}_{0.2} \mathrm{Ga}_{0.8} \mathrm{As}$ DWELL than that in $\mathrm{InAs} / \mathrm{In}_{0.15} \mathrm{Ga}_{0.85} \mathrm{As}$ DWELL. According to Table, we believe that the increase of $x$ can lead to the decrease of the effective mass in $\mathrm{In}_{x} \mathrm{Ga}_{1-x}$ As. Moreover, in the presence of strains, the energy gap of $\operatorname{In}_{x} \mathrm{Ga}_{1-x}$ As decreases with the value of $x$ increasing. Hence, the potential decreases with the value of $x$ increasing. At last, the increase of the value of $x$ effectively lowers the electron states in the DWELL.

The value of $x$ taken in $\operatorname{In}_{x} \mathrm{Ga}_{1-x} \mathrm{As}$ is 0.15 in Fig. 3a and 0.2 in Fig. 3b. As a function of the thickness of the well, the conduction subbands of the DWELL heterostructure is shown in Fig. 3. The other parameters are set the same as in Fig. 3a and Fig. 3b, namely, $L=15 \mathrm{~nm}+2 R, R=7.5 \mathrm{~nm}$ and $L_{z}=60 \mathrm{~nm}$.

From Fig. 3, it can be seen that all bound states of the DWELL decrease with the thickness of the well increas-

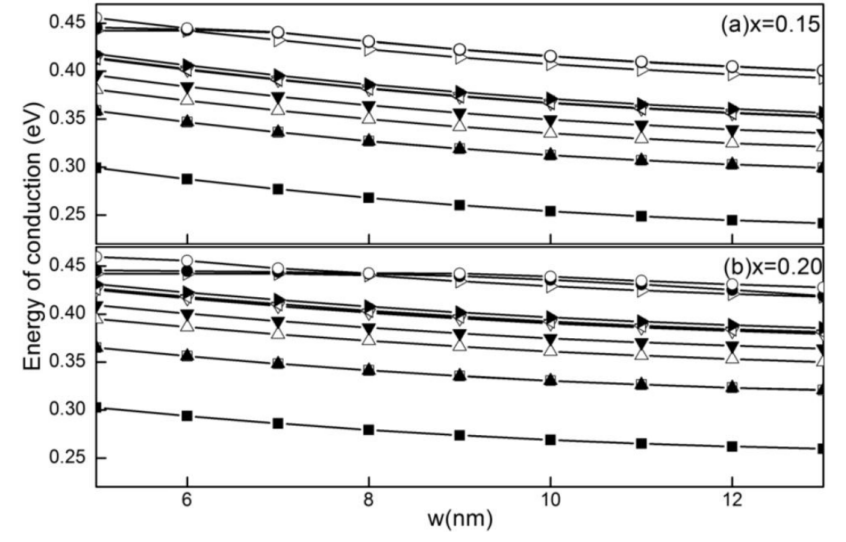

Fig. 3. Conduction subband as a function of the (a) InAs $/ \operatorname{In}_{0.15} \mathrm{Ga}_{0.85} \mathrm{As}$ and (b) $\mathrm{InAs} / \mathrm{In}_{0.2} \mathrm{Ga}_{0.8} \mathrm{As}$ layer width $(\mathrm{w}-\mathrm{h})$ for the DWELL heterostructure with $L=$ $15 \mathrm{~nm}+2 R, h=7.5 \mathrm{~nm}$, and $L_{z}=60 \mathrm{~nm}$.

ing. In addition, when $w=5 \mathrm{~nm}$, the lowest state in Fig. 3a and in Fig. 3b is almost the same $(0.3 \mathrm{eV})$. With the thickness of the well increasing, the ground state in Fig. 3a becomes lower than that in Fig. 3b. For example, when $w=13 \mathrm{~nm}$, the ground state in Fig. $3 \mathrm{a}$ is $0.24 \mathrm{eV}$, but that in Fig. 3b is $0.255 \mathrm{eV}$.

Figure 4 shows the calculated absorption spectra of the DWELL structures with different $\operatorname{In}_{0.15} \mathrm{Ga}_{0.85} \mathrm{As}$ layer widths at $50 \mathrm{~K}$. For simplicity, we fix the location of QDs at the center of the InGaAs layer during the calculation. The electron concentration is fixed as: $5.9 \times 10^{18} \mathrm{~cm}^{-3}$, which satisfies the fact that the Fermi level is just above the ground state but does not reach the first excited one. The electric vector of incident light is assumed to be perpendicular to the growth direction. We can find that not all possible transitions can be seen in the spectra due to their weak oscillator strengths or due to the shallow depth of the higher energy levels involved [23].

The most impressive two absorption peaks lie in the long-wave infrared (LWIR) and far-infrared (FIR) ranges, respectively. The FIR peak corresponds to the transition between two bound states below the $\operatorname{In}_{0.15} \mathrm{Ga}_{0.85} \mathrm{As}$ conduction-band edge [23]. The LWIR one is believed to stem from the transition between the ground state and high bound state below the GaAs conduction-band edge [23]. Moreover, comparing Fig. 4a with Fig. 4b, it can be judged that the peak of absorption spectra shows a dramatic red shift with the thickness of $\operatorname{In}_{0.15} \mathrm{Ga}_{0.85} \mathrm{As}$ layers changing from 7 to $9 \mathrm{~nm}$. The LWIR peaks locate at 10.46 and $10.53 \mu \mathrm{m}$ in Fig. $4 \mathrm{a}$ and Fig. $4 \mathrm{~b}$, respectively. 


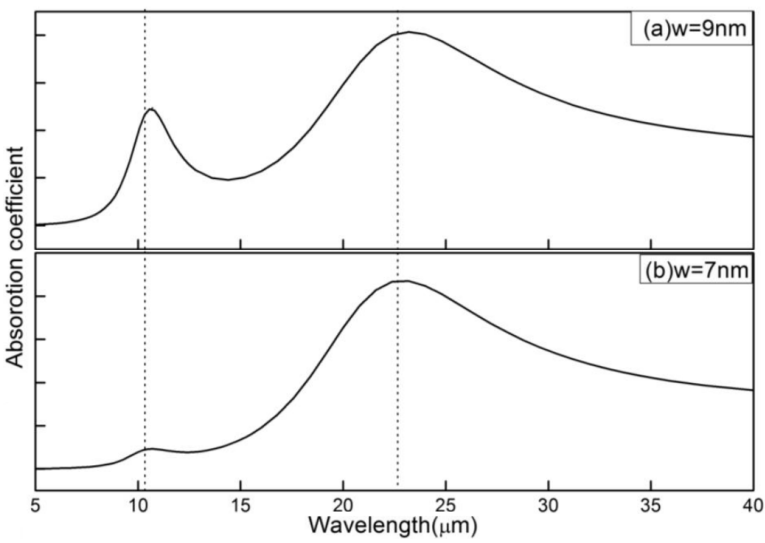

Fig. 4. Absorption spectra as a function of the $\mathrm{In}_{0.15} \mathrm{Ga}_{0.85} \mathrm{As}$ layer width $(\mathrm{w}-\mathrm{h})$ at $50 \mathrm{~K}$ for the InAs / $\mathrm{In}_{0.15} \mathrm{Ga}_{0.85}$ As DWELL with $L=15 \mathrm{~nm}+2 R, h=$ $7.5 \mathrm{~nm}, w=9 \mathrm{~nm}(\mathrm{a}), w=7 \mathrm{~nm}(\mathrm{~b})$ and $L_{z}=60 \mathrm{~nm}$.

Figure 3a can help us to explain this phenomenon. In Fig. 3a, when the thickness of $\operatorname{In}_{0.15} \mathrm{Ga}_{0.85}$ As layers is $7 \mathrm{~nm}$ and $9 \mathrm{~nm}$ the energy gap between the ground state and high bound state below the GaAs conduction-band edge is 0.1185 and $0.1178 \mathrm{eV}$, respectively. For the same reason, the red shift of FIR peaks arise from the changing of energy gap of two bound states below the $\mathrm{In}_{0.15} \mathrm{Ga}_{0.85}$ As conduction-band edge. The above means that the operating wavelength of $\operatorname{InAs} / \operatorname{In}_{0.15} \mathrm{Ga}_{0.85} \mathrm{As}$ DWELL can be controlled through changing the thickness of $\operatorname{In}_{0.15} \mathrm{Ga}_{0.85}$ As layers.

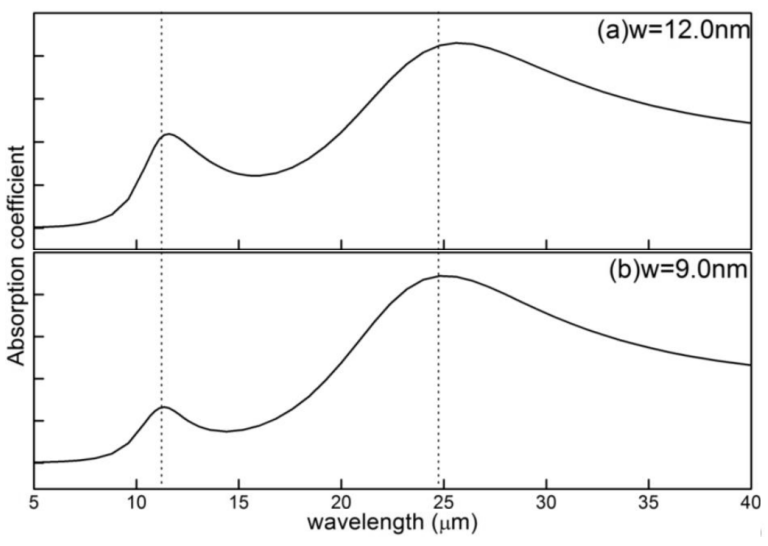

Fig. 5. Absorption spectra as a function of the $\mathrm{In}_{0.15} \mathrm{Ga}_{0.85} \mathrm{As}$ layer width $(\mathrm{w}-\mathrm{h})$ at $50 \mathrm{~K}$ for the InAs / $\mathrm{In}_{0.15} \mathrm{Ga}_{0.85}$ As DWELL with $L=15 \mathrm{~nm}+2 R, h=$ $7.5 \mathrm{~nm}, w=12 \mathrm{~nm}(\mathrm{a}), w=9 \mathrm{~nm}(\mathrm{~b})$, and $L_{z}=60 \mathrm{~nm}$.

Figure 5 presents the calculated absorption spectra of the DWELL structures with different $\operatorname{In}_{0.2} \mathrm{Ga}_{0.8}$ As layer widths at $50 \mathrm{~K}$. The thicknesses of the $\mathrm{In}_{0.2} \mathrm{Ga}_{0.8} \mathrm{As}$ are taken as $9 \mathrm{~nm}$ and $12 \mathrm{~nm}$, respectively, in Fig. 5a and b. The electron concentration is fixed as $5.1 \times 10^{22} \mathrm{~cm}^{-3}$, which satisfies the fact that the Fermi level is just above the ground state but does not reach the first excited one. The other parameters are set the same as in Fig. 4. Comparing Fig. 5a with b, it can be seen that the peak of absorption spectra shows a dramatic red shift with the thickness of the $\operatorname{In}_{0.2} \mathrm{Ga}_{0.8}$ As layers changing from 9 to $12 \mathrm{~nm}$. Moreover, comparing Fig. 5b with Fig. 4a, the whole absorption spectra show an obvious red shift. This implied that the operating wavelength of InAs/ $\mathrm{In}_{1-x} \mathrm{Ga}_{x} \mathrm{As}$ DWELL can be controlled through changing the value of $x$ in $\operatorname{In}_{x} \mathrm{Ga}_{1-x} \mathrm{As}$.

\section{Conclusion}

In summary, on the basis of the effective-mass envelope function theory, we have studied the energy band and absorption coefficient of the $\operatorname{InAs} / \operatorname{In}_{x} \mathrm{Ga}_{1-x}$ As quantum DWELL structures with the QD of an ellipsoid shape in the mode. It is found that the InAs $/ \mathrm{In}_{0.2} \mathrm{Ga}_{0.8} \mathrm{As}$ quantum DWELL has lower ground states than InAs/ $\mathrm{In}_{0.15} \mathrm{Ga}_{0.85} \mathrm{As}$ quantum DWELL. When the thickness of the $\operatorname{In}_{0.15} \mathrm{Ga}_{0.85}$ As layer increases from $7 \mathrm{~nm}$ to $9 \mathrm{~nm}$, the calculated absorption coefficient spectra of InAs/ $\mathrm{In}_{0.15} \mathrm{Ga}_{0.85} \mathrm{As}$ quantum DWELL take a red shift. In the InAs $/ \mathrm{In}_{0.2} \mathrm{Ga}_{0.8} \mathrm{As}$ quantum DWELL, a red shift of the absorption coefficient also can be checked when the $\mathrm{In}_{0.15} \mathrm{Ga}_{0.85}$ As layer increases from $9 \mathrm{~nm}$ to $12 \mathrm{~nm}$. Moreover, the absorption coefficient spectra of InAs/ $\mathrm{In}_{0.2} \mathrm{Ga}_{0.8}$ As DWELL shows an obvious red shift comparing with that of InAs $/ \operatorname{In}_{0.15} \mathrm{Ga}_{0.85}$ As DWELL when the $\operatorname{In}_{x} \mathrm{Ga}_{1-x} \mathrm{As}$ layer is $9 \mathrm{~nm}$. These phenomena give us a method to control the operating wave length of InAs/ $\mathrm{In}_{1-x} \mathrm{Ga}_{x} \mathrm{As}$ DWELL through changing the thickness of $\mathrm{In}_{1-x} \mathrm{Ga}_{x}$ As layers and the value of $x$ in $\operatorname{In}_{x} \mathrm{Ga}_{1-x} \mathrm{As}$.

\section{Acknowledgments}

Project supported by the National Key Basic Research Program of China (2012CB934201), the National Natural Science Foundation of China (11074129), the Natural Science Foundation of Tianjin (09JCYBJC04100, 08JCYBJC14800) and the Fundamental Research Funds for the Central Universities (65011791).

\section{References}

[1] S. Lee, J. Kim, L. Jönsson, J.W. Wilkins, Phys. Rev. B 66, 235307 (2002).

[2] A. Franceschetti, H. Fu, L.W. Wang, A. Zunger, Phys. Rev. B 60, 3 (1999).

[3] A.J. Williamson, L.W. Wang, A. Zunger, Phys. Rev. B 62, 19 (2000).

[4] H. Jiang, J. Singh, Phys. Rev. B 56, 8 (1997).

[5] P. Hawrylak, Phys. Rev. B 60, 8 (1999).

[6] L. Landin, H. Pettersson, M. Kleverman, M. Borgström, X. Zhang, W. Seifert, L. Samuelson, J. Appl. Phys. 95, 12 (2004).

[7] S. Krishna, S. Raghavav, G. Winckel, Appl. Phys. Lett. 82, 16 (2003).

[8] D.P. Popescu, P.G. Eliseev, K.J. Malloy, J. Appl. Phys. 97, 093702 (2005). 
[9] R.S. Attaluri, S. Annamala, K.T. Poani, A. Stintz, S. Krishna, J. Appl. Phys. 99, 083105 (2006).

[10] T.V. Torchynska, J.L. Casas Espinola, L.V. Borkovska, J. Appl. Phys. 101, 024323 (2007).

[11] E. Ki, Z. Chen, A. Madhukar, J. Appl. Phys. 79, 20 (2001).

[12] A. Stintz, G.T. Liu, A.L. Gray, J. Vac. Sci. Technol. $B$ 18, 3 (2000).

[13] E. Melezhik, O. Korotchenkov, J. Appl. Phys. 105, 023525 (2009).

[14] L. Höglund, K.F. Karlsson, P.O. Holtz, Phys. Rev. B 82, 035314 (2010).

[15] S.D. Lin, C.P. Lee, J. Appl. Phys. 93, 5 (2003).

[16] M.A. Naser, M.J. Deen, D.A. Thompson, J. Appl. Phys. 100, 093102 (2006).
[17] S. Nojima, Phys. Rev. B 41, 14 (1990).

[18] A. Amtout, S. Raghavav, P. Rotella, J. Appl. Phys. 96, 7 (2004).

[19] R. Chen, H.Y. Liu, H.D. Sun, Solid State Commun. 150, 707 (2010).

[20] S. Krishna, S. Raghavan, G. von Winckel, Appl. Phys. Lett. 83, 14 (2003).

[21] S. Li, J. Xia, Z.L. Yuan, Z.Y. Xu, Phys. Rev. B 54, 16 (1996).

[22] S. Li, J. Bai, Phys. Rev. B 55, 23 (1997).

[23] X. Han, J. Li, J. Wu, J. Appl. Phys. 98, 053703 (2005). 